This PDF is a selection from a published volume from the National Bureau of Economic Research

Volume Title: International Differences in the Business Practices and Productivity of Firms

Volume Author/Editor: Richard B. Freeman and Kathryn L. Shaw, editors

Volume Publisher: University of Chicago Press

Volume ISBN: 0-226-26194-8

Volume URL: http://www.nber.org/books/free07-1

Conference Date: January 2006

Publication Date: September 2009

Chapter Title: Productivity Differences in an International Pharmaceutical Firm

Chapter Author: Tor Eriksson, Niels Westergaard-Nielsen

Chapter URL: http://www.nber.org/chapters/c0444

Chapter pages in book: (p. 173 - 192) 


\section{Productivity Differences in an International Pharmaceutical Firm}

Tor Eriksson and Niels Westergaard-Nielsen

\subsection{Introduction}

The differences in productivity growth between the United States and Europe since the early 1990s have been explained by differences in the speed of adopting the new information and communication technologies and in making full use of the new technologies (see, e.g., Feldstein [2003], van Ark, O'Mahoney, and Timmer [2008]). The argument is that in order to fully exploit the possibilities to enhance productivity with the help of the new information and communication technologies, implementation of the latter have to be accompanied by changes in work organizations and practices: decentralized decision making, more teamworking, and jobs with broader skills. Thus, higher rates of adoption of Information and Communication Technology (ICT) and, hence, stronger productivity growth in the United States has been facilitated by the less regulated American labor markets, which make it easier to implement the changes in work organizations that, combined with ICT, elevate productivity. Another factor reinforcing the difference between the two continents are the stronger management incentives in U.S. firms, owing to the more widespread use of stock options, bonuses, and other incentive pay programs for managers. Naturally, there are also other factors that can have contributed to the increase in productivity, such as changed policy regime and deregulation of several markets, but

Tor Eriksson is a professor of economics at the Aarhus School of Business, University of Aarhus. Niels Westergaard-Nielsen is a professor of economics and director of the Center for Corporate Performance at the Aarhus School of Business, University of Aarhus.

Acknowledgments: We are grateful to the firm giving us time and data for this study, Frederic Warzynski for helpful discussions, and participants of the NBER-Sloan project, as well as a referee for valuable comments on an earlier version of this chapter. 
for an understanding of the U.S.-Europe differential, differences in labor market regulations and institutions are the prime candidates. Following, we will provide some micro-level evidence on this issue, making use of a cross-country comparison of developments of a Danish and a U.S. plant within a single firm.

It should be noted, however, that from a general U.S.-Europe comparison perspective, Denmark has rather atypical labor market institutions and regulations. In this respect Denmark is not a typical European country and as a matter of fact does not do a good job in representing the other Scandinavian countries either. A key characteristic of Danish industrial relations is the socalled "Danish model," according to which many issues related to the labor market are regulated not by legislation, but by agreements between employers and their employees. This is true not only for wages, but for regulation of working time, employment protection, notification of lay-offs, and so forth. However, the "Danish model" does not completely exclude regulation; legislation regulates holidays and work environment and safety, but these are exceptions. Another distinguishing feature of Danish labor markets is the combination of labor market flexibility and income security, oftentimes called "flexicurity." Job security legislation is very liberal by European standards: there is no experience rating in the unemployment insurance system, the replacement ratios of the unemployment benefits are among the highest in the world, and most social insurance benefits, vacation rights, and pensions are transferable across employers. Hence, costs of labor mobility are relatively low for both employers and employees.

Our analysis is also related to another recent literature on the importance of new work practices and new work organizations for corporate performance; for a review, see Ichniowski and Shaw (2003). These studies point to flattening of hierarchies, broadening and enrichment of job designs, increased functional flexibility, teamwork, and empowerment of workers as sources of improving productivity. The idea behind many of the new work practices used is often the opposite of the traditional way of thinking in economics, according to which, ever since Adam Smith's pin factory study, productivity improvements chiefly are thought of as arising from specialization.

Now, of course, nobody is claiming that the work practices and new payment systems associated with them or empowerment of workers always work to the benefit of the firm. Thus, several studies conclude that in order for changes in work organizations to have profound effects, they have to be bundled with changes in other practices (training, compensation, etc.); see Ichniowski and Shaw (2003). An important restriction on empowering workers is that profitability is likely to decline before productivity stops improving (Freeman and Lazear 1995). Introduction of performance pay is sometimes associated with great improvements of a company's performance 
(Lazear 2000); other times abandoning performance pay and adoption of input-based pay leads to better performance (Freeman and Kleiner 2005). Changes in information and communication technologies has indeed made it possible to decentralize the organization of firms, but can also enable firms to reduce their worker's decision-making authority and to monitor them more closely than before (Hubbard 2000, Acemoglu et al. 2007).

The lesson from the burgeoning literature on new workplace practices, empowerment of workers, and the impact of the new information and communication technologies seems to be that sometimes adopting them is good, but other times it is not. Thus, the conjecture that differences in the rate of adoption of new work organizations to support the introduction of information and communication technologies could explain differences in productivity does not necessarily follow.

\subsection{The Firm and the Industry}

The firm we are concerned with in the current study is a large multinational firm in the pharmaceutical industry, the mother company of which is located in Denmark. For convenience, we henceforth call the firm AB. Internationally, this firm faces strong competition from three or four other producers, but so far $\mathrm{AB}$ has been quite successful. Thus, $\mathrm{AB}$ is considered as one of the big players in the market for the specific medicine it produces. The international market for the drug $\mathrm{AB}$ is producing is one of the fastest growing in the whole pharmaceutical industry. In Denmark AB is not only known for its successful performance during several years in a row, but is also widely considered to be among the best employers in the country because of its labor-friendly policies. Furthermore, AB is known for its corporate social responsibility and its focus on environmental issues in particular. But also equal opportunity and concerns for work-life balance are important elements of AB's profile. When AB has opened a production plant in a new country, it has to a large extent transferred the same company values to the new location. At the same time, $\mathrm{AB}$ has had to account for differences in the economic environment its plants are operating.

\subsubsection{The Production Technology}

All the raw material for the medicine is produced by a single AB factory located in Denmark and is delivered as a crystalline product to all the other AB plants in different parts of the world. These plants in turn make different dilutions of the crystals for different products. This formulation, as it is called, is carried out in a separate unit at each production plant. In all plants there is still another unit where the filling process takes place. Each plant has a number of filling lines, which used to be plant-specific; that is, designed and built for that factory only. Now this has changed as there are 
standardized filling machines that can be bought from manufacturers and can be adapted to the local circumstances.

Because of the strict regulations characterizing the pharmaceutical industry, a considerable part of the processes have to be done in an antiseptic environment. This requires special building features as well as special training by workers. In the production of the medicine in our case firm, there are two antiseptic levels, and the workers have to meet certain qualification requirements for working at both of them. It usually takes two years to take the tests that qualify the worker for the highest level of antiseptic work. The antiseptic requirements make the filling vulnerable to faulty techniques and hence, filling is much more complex and expensive than, for instance, beer bottling. Consequently, for the profitability of the production process, maintaining high quality while simultaneously reducing operation time of machines and workers are key.

\subsubsection{Regulation}

In the two plants we are examining, the products are to be marketed in the U.S. market, and as a consequence, both the production of the raw material and the filling operations are regulated by the U.S. Food and Drug Administration (FDA). The regulation implies that there are strict requirements as to data collection, procedures, and employees' awareness and knowledge about working in antiseptic environments. The FDA approval takes a long time to obtain, but is lost in a relatively short time and is, therefore, considered as one of the biggest assets in the industry; indeed, survival is conditional on it. Thus, production quality is crucial. In order to meet the FDA standards $\mathrm{AB}$ has to invest large resources in hiring and training the right people. Five to eight years ago, the main focus of the company's strategy was on securing and maintaining the FDA approval. Thus, the major part of managerial resources was used on improving the quality aspects of production.

Today, the personnel are the single most important input in production of the drug since machinery and equipment for the filling lines can be bought on the market. Earlier, the filling lines were customer built; hence, a firm could compete on the quality side by design and construction of superior equipment. As this is no longer the case, improving productivity on the existing lines has become a central parameter of competition. The main vehicle in these efforts at $\mathrm{AB}$ has been a reengineering project using the lean production approach (henceforth referred to as the LEAN project). There are many tools in this process. Basically, it is the manner technicians and the filling staff work together, the way teams are organized, what teams do when a member is absent, employee training, and the placement of working hours.

Where FDA regulations do not apply, national or EU authorities are performing similar regulations and controls. For our study it is important to notice that the FDA is applying the same standards to the two plants studied. Next, we turn to look at the two plants in more detail. 


\subsection{The Two Case Plants}

The AB company has several production sites in Denmark, one plant in the United States, and a number of additional plants in a number of other countries. In our research reported following we have predominantly focused on the U.S. plant and the main Danish plant, which is the oldest plant in the firm. At a later stage it turned out to be easier to obtain comparable data from one of the other Danish plants, which also resembles the American plant in several respects. Thus, in section 6.4.2, we will also make use of some information from this other Danish plant.

The main production processes at the two plants studied are formulation and filling of the medicine. At the two plants the medicine is filled on two types of vials: a traditional one and a modern, easier-to-use vial, henceforth called P1 and P2, respectively. One thing the two plants have in common is that they both supply to the U.S. market. Consequently, also the Danish plant has to meet all the requirements of the FDA; in fact, the plant in Denmark is the only one within AB and outside the United States that is delivering the drug to the American drug market.

In order to understand how differences in productivity and efficiency over time as well as between plants arise, it is important to know what the sources of nonproduction are. Consider the operations of a filling during a week. Of the total 168 hours available for production a considerable part is not due to:

Maintenance of the equipment

Validation of equipment

Testing new products

Changeover and setup (that is, time between batch runs)

Cleaning

The proportion of the week when the equipment is not available for production can easily be as high as 20 to 30 percent. Consequently, technological and organizational changes that reduce the time the equipment is idle are crucial. Another reason for low productivity is interruptions in production, especially filling, which give rise to losses during operation. This form of downtime makes up a considerable proportion of the total time when the equipment is available for production. Finally, for total efficiency, quality of the products play a role as some part of the production during a batch will be scrapped because it does not meet the high antiseptic and other quality standards. Thus, reduction of losses due to nonavailability of equipment, losses during operation, and quality losses constitute important ways of improving productivity.

Although the two plants have many things in common, there are also some distinct differences. One is that the Danish plant has seven lines of filling stations while the U.S. plant only has four. Another difference is that the plant in the United States is operating around the clock with work organized in two 
twelve-hour shifts, whereas in the plant in Denmark work is organized in two eight-hour shifts, with cleaning commencing after the second shift. The reason for this is historical: the highest antiseptic level is in the middle of the old plant building and is physically located in a big room that has to be cleaned at the same time. The American plant is younger and built in such a way that there are four distinct lines that can be run and cleaned separately.

A third difference is that the Danish plant is also doing trial fillings and is, therefore, frequently producing relatively small batches. The batch size is important not only because it affects the frequency of changeovers, but also because the filling line always has to be cleaned between two batch runs. This is because regulation stipulates that one should be able to track each batch from the formulation to the final product stage. This is not without consequences for how production can be organized and affects operation times. Moreover, as the plant in Denmark is not working around the clock, a new, larger batch will not be started up if the previous batch is finished in the middle of the day. Instead, the time will be used for maintenance. We actually saw this happen when we visited the Danish plant. The consequence is that there will be downtime that cannot always be productively used. At the U.S. plant this problem seldom arises.

Because of the differences in shift systems as well as in filling technologies, one would expect that productivity is lower at the Danish plant. Hence, it is somewhat surprising that in fact the American plant used to have the lowest productivity among all $\mathrm{AB}$ plants, whereas the Danish plant under study ranked in the middle. This has, however, changed after the organizational changes in the U.S. plant that took place in spring 2003. In section 6.3.1, we will explain in more detail how this was accomplished.

\subsubsection{Industrial Relations}

Industrial relations differ vastly between the two locations. In the U.S. plant there are no trade unions and the general attitude of the management is rather to provide workers with benefits of one or the other type to keep the unions out. Furthermore, the factory is located in a state where union activity is considerably lower than the national average. At the Danish plant the situation is completely different. Here workers are organized in strong unions and there is a long tradition of cooperating with the local union representative who is elected by the workers to represent them toward the management. This is a model that for many decades has worked well in many Danish firms. The model rests on the mutual trust (social capital) that has been built up over the years.

The differences in industrial relations ${ }^{1}$ are also reflected in the organi-

1. The differences in span of control are likely not to be only due to differences in industrial relations, but also due to the fact that the skill level of the production workers at the U.S. plant is considerably lower than that of their Danish colleagues. 
zational structure of the two plants. ${ }^{2}$ While the average span of control of managerial employees at the Danish plant varies between twenty-four and thirty during years 2003 to 2007, the corresponding figures for the U.S. plant vary between five and six. As the production technologies are basically the same, this naturally implies that the proportion of managerial employees is higher at the U.S. plant. This in turn means that the annual promotion rates from worker to managerial employee is substantially higher in the U.S. plant ( 2.4 to 3.5 percent) than in the Danish plant ( 0.3 to 0.4 percent).

As we know from the relational contracts literature (Baker, Gibbons, and Murphy 2002), when a relationship is built on reputation and trust, major changes are oftentimes difficult and costly to implement.

\subsubsection{The Danish Plant}

The Danish plant has for many years had a reputation for paying high wages to their production workers - as much as 20 percent more than in other companies employing similar workers ${ }^{3}$ - and for offering good working conditions in general. ${ }^{4}$ As a consequence, it should have no problems in recruiting highly productive workers. However, a considerable portion of the workers have been hired as a result of being referred to by existing workers. In several cases the incumbents (the teams) actually chose new employees, or at least had a nontrivial influence on who was recruited. As a result, many workers knew each other before they became colleagues and were sometimes even family with each other. Of course, this meant that those who were employed were not necessarily always the best hires available and, moreover and probably more importantly, because the employees had strong ties to each other, their bargaining power toward their superiors was unusually strong.

Surprisingly, until recently nothing had been done to test workers before they were employed. ${ }^{5}$ In fact, testing was actually forbidden according to an agreement between the firm and the local trade union representatives. Many production workers have some form of postcompulsory vocational education, or are skilled workers with apprenticeship training. As a result of the low worker turnover, the workforce at the plant typically has long tenures.

Nonproduction personnel are well paid too, but at competitive rates. Also for this category of employees the turnover rate is relatively low - on average

2. See Smeets and Warzynski (2008) for a detailed analysis that also includes other AB plants than those in focus here.

3. Firm AB uses performance pay for most of its employees at the Danish plant. Production workers are the exception. Thus, all team members receive the same pay.

4. As one of the managerial employees told us, the wages are too high insofar that the demotivated workers have no incentives to leave because of the large drop in earnings they would suffer. His estimate of the proportion of demotivated and poor employees locked in by the high wages was in the 5 to 10 percent range.

5. Buying peace at the Danish plant was very important for the top management of the firm. As one manager we interviewed expressed it: "every time there is the slightest (industrial relations) problem in this plant it will be discussed at the board level." 
3 percent, annually - indicating that there are also other attractive features with the workplace than the compensation.

In general, the Danish labor market is not characterized by strong job security legislation. In fact, regulation of the termination of employment relationships is one of the most liberal in Europe and is at par with the United Kingdom and Switzerland. But at AB, employment protection is extensive and is an important part of the company's personnel policies. Thus, if an employee does not fit his or her present job, he or she is offered another job within the firm and the firm pays for the training for the new job. If this does not work out either, the person can be laid off, but will typically receive help in the reallocation.

\subsubsection{The U.S. Plant}

In hiring workers the American plant has to compete with a number of other pharmaceutical plants in the nearby area, which is one of the major pharmaceutical clusters in the United States. As a result, they tend to recruit from the same pool of workers and wages are on par with those of the competing firms. However, according to the plant's HR-manager the nonwage benefits are somewhat higher at AB's U.S. plant than in the competing plants in the same region.

Average tenure for all employees is three years and the average age of all employees is 39.6. As can be seen from table 6.1, worker turnover was rather high in 1999 to 2000 but has decreased thereafter. At the time of the interview it was to land at 17 percent for the year 2004. Thus, the employee turnover rates at the U.S. plant are vastly higher than at the Danish plant. The earlier higher turnover should be seen in the perspective that the U.S. plant has only existed for twelve years. The increase in mobility in 2004 is chiefly among hourly paid workers and is probably due to some depreciation in compensation and working conditions. The reduction of employee turnover from 1999 to 2002 was due to policies specifically aiming at retaining workers.

The predecessor of the current HR-manager had tried to implement selfmanaged teams that were principally designed in the same way as at the Danish plant. This organizational change turned out be a failure and was quickly abandoned. A management team member summarized these events by saying: "self-managed teams are risky in regulated industries." In order to reduce employee turnover, a new layer of supervisors, corresponding to the "team leaders" at the plant in Denmark, was recruited in 2003. There was also a change in the compensation program to include a bonus scheme, which contributed to a reduction in turnover. Another factor contributing

Table 6.1 Employee turnover at the U.S. plant (in percent)

\begin{tabular}{cccccc}
\hline 1999 & 2000 & 2001 & 2002 & 2003 & 2004 \\
\hline 30.1 & 20.2 & 12.1 & 10.2 & 13.4 & 17.0 \\
\hline
\end{tabular}


to problems of retaining employees was that too many hires were ramped up at the same time, which led to lower average quality of the hires and consequently higher turnover.

Retaining employees in a highly competitive labor market like the pharmaceutical cluster the $\mathrm{AB}$ plant is located in is, of course, a major challenge. The hourly paid workers at the U.S. plant are paid less in terms of base salary than workers at the major local competitors, but are on the other hand paid higher bonuses and are offered more generous retirement benefits. A negative feature of working at AB's American plant is that it is only closed for two days (Christmas and Thanksgiving) per year. This makes working there "like working at a hospital," something that is not popular among the employees.

One of the elements in the compensation package that used to make the plant an attractive workplace was that annual paid time out (PTO) - forty hours per year - was also paid to hourly paid workers. However, this changed as of 2005. Now, PTO cannot be used anymore for reasons of bad weather, and in order to use PTO the employee has to notify the plant twelve hours in advance, otherwise the first two hours are deducted from the attendance record in the following year. More important for retaining workers is the relatively generous $401 \mathrm{~K}$ Retirement Savings Program: the employer matches 8 percent (gross) of the earnings and furthermore, matches 1 percent for the employee's optional 2 percent contribution. This program is more generous than that of other firms in the local labor market and explains the success in retaining workers as it is likely to attract workers who consider staying in the industry during their entire labor market careers. A problem in attracting and retaining hourly paid workers is that there are relatively few promotion possibilities ${ }^{6}$ for them. To improve on this, the earlier requirement that supervisors should have a college degree has been relaxed.

The U.S. plant's HR-manager complained about difficulties in recruiting enough qualified workers. Training courses have been organized in collaboration with the local community college and firms in the nearby pharmaceutical cluster in order to solve this problem.

The technicians, the supervisors, and the managers are all employed "at will," which means that they can be fired or laid off without notice, but to the best of our knowledge this has rarely happened.

\subsection{Analysis-the Main Findings}

\subsubsection{Decision to Change}

After a period of several years during which $\mathrm{AB}$ had been mainly focusing on the quality aspect of its production, increasing productivity and lowering

6. There are three grade levels and a worker can advance to the highest grade in five years' time. 
production costs became the new focal point. The shift in focus was launched as a reengineering project in the lean production tradition, which was started at both plants in 2003. The main emphasis was on improving the work processes in order to enhance productivity. The motivation for starting this process in the filling process was that it was widely recognized that there was lots of idle time in the filling lines. It was conceived that one reason was that the "self-managed teams" had largely been in charge of the time planning and time use, with poor utilization of time as a consequence.

With the lackluster productivity record in the U.S. plant, there is little doubt that the management in the plant felt strongly that they had to make a turnaround. As a consequence, a number of changes were initiated. First of all a new production manager was employed. He had experience of working for many years in the utilities industry and more recently at a major consultancy firm. It was frequently pointed out to us that one of his "advantages" was that he had no previous experience of the pharmacy industry. This enabled him to take a fresh view of things and to take initiatives unseen in the industry before. He employed a number of new managers, including the current human resources manager.

Early on in the process, it was realized that one important element in a strategy to improve productivity was to change production to an aroundthe-clock operation, as this would foster communication and continuity in operations. Earlier, the plant was using a multiple shifts system with eightand twelve-hour shift arrangements. As from early 2003, a standardized shifts system with twelve-hour shifts only and a work schedule following a two-week repeating cycle was introduced. As a consequence of this change, the labor force had to be doubled. Because none among the existing workers wanted to work on the night shift, two completely new teams had to be recruited. Ordinary workers were mainly recruited from the other pharmaceutical firms in the area and some were also employed directly from school (a 180 hours education preparing employees for work in the pharmaceutical industry provided by a local community college). The new employees were only hired for the night shift but they were promised to be moved to the day shift according to seniority and as vacancies opened up. There was a small wage premium of one dollar per hour for working at the night shift, but otherwise employment conditions were the same as for the day shift workers. In late 2004 , the night shift premium was increased to $\$ 2.50$ per hour to reduce worker turnover.

Technicians were recruited among ex-military personnel. The submariners in particular proved to be good workers in the filling lines "because they were used to dealing with problems without calling for assistance." Supervisors were also recruited among ex-military officers, mainly those with a technical college education.

After a relatively short introduction and training at the community college, the two-shift, round-the-clock production started in 2003. The produc- 
tivity of the night shift fairly quickly reached levels comparable to those of the day shift. Together with the day shift, the U.S. plant was now producing at 50 percent of its capacity. It is believed that approximately 80 percent capacity utilization is the maximum, because of the FDA regulations, cleaning, and so forth.

The program for enhancing productivity also included changes in the organization of work at the filling lines. The aim was to simplify batch production procedures in order to reduce the number of errors. Training of employees became more standardized and training programs were written down and hence became more formalized. In that sense one can say that the work organization got a more Taylorist flavor than before. But some other changes went in the opposite direction. Thus, jobs typically became broader; for example, maintenance workers were now also expected to do filling work. This was not popular among the workers, but was nevertheless implemented by the management. The idea was to put more emphasis on preventive maintenance and to shorten the waiting time when a technician was needed. Another unpopular change was a shortening of breaks.

In order to support these changes and the LEAN program in general, the bonus program as from 2004 gives a bonus for LEAN participation and promotes cross-functional cooperation. Performance measurement is on the level of the individual worker, but performance bonuses accrue to teams. All the changes mentioned previously - in work organization, jobs, shifts, and remuneration -were controversial, and there was a lot of resistance that, as already noted, also took the form of an increase in workforce turnover. Thus, as predicted by theory (Lazear 2000), changes in compensation and work organization were accompanied by sorting of workers.

\subsubsection{The Change: Different Outcomes}

As can be seen from figure 6.1, total production at the U.S. plant has increased steadily since production started. Employment has almost tripled since the first years. Productivity has increased, too-see figure 6.2-but not uninterruptedly. In fact, productivity increased strongly during the first years of operation, most likely as a consequence of the management gaining more experience of running the plant and other employees of carrying out their tasks more efficiently. As from 2000, there is a considerable dip and productivity recovers slowly (and is higher only four years later). The dip in productivity coincides with the years of high labor turnover and the failure of organizing work in self-managed teams. The substantial improvement after the implementation of the turnaround in 2003, which happened without an increase in the workforce, indicates that high worker turnover and team organization can be detrimental for productivity in this type of production.

We also have access to monthly data: for the U.S. plant for 2004 and 2005, and for the Danish plant for 2004 to 2006. One should remember that the 


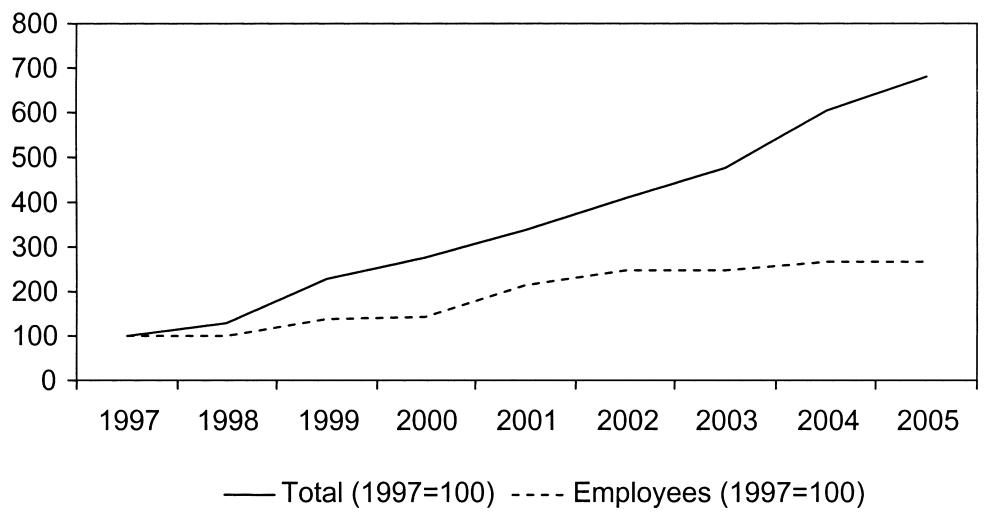

Fig. 6.1 Development in employment and production at the U.S. plant, 1997-2005

Productivity $(1997=100)$

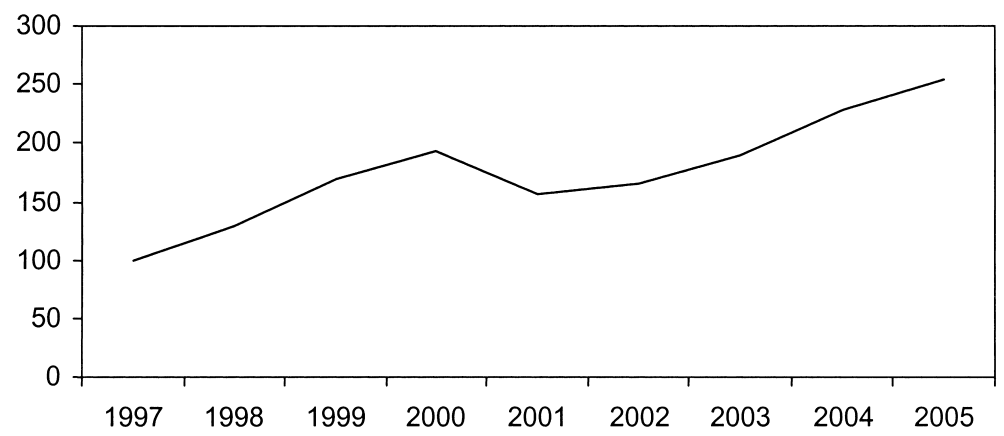

Fig. 6.2 The development of annual productivity at the U.S. plant, 1997-2005

new production scheme was implemented in the very first months of 2003, and so, the figures for 2003 are likely to be affected by the management and workers (many of whom at the U.S. plant were newly hired) gaining experience from the new scheme. As can be seen from figures 6.3 and 6.4, production of both products at both plants displays considerable variation across months. Although not easily discernible from the figures, there is an increase in production over time.

As was discussed in section 6.3, productivity at the plants is determined by the up-time of the equipment and the efficiency by which the equipment is operated. Somewhat surprisingly, comparable information about operating machine hours does not exist for both plants. Figure 6.5 gives the monthly availability of machines at the U.S. plant. From this it can clearly be seen 


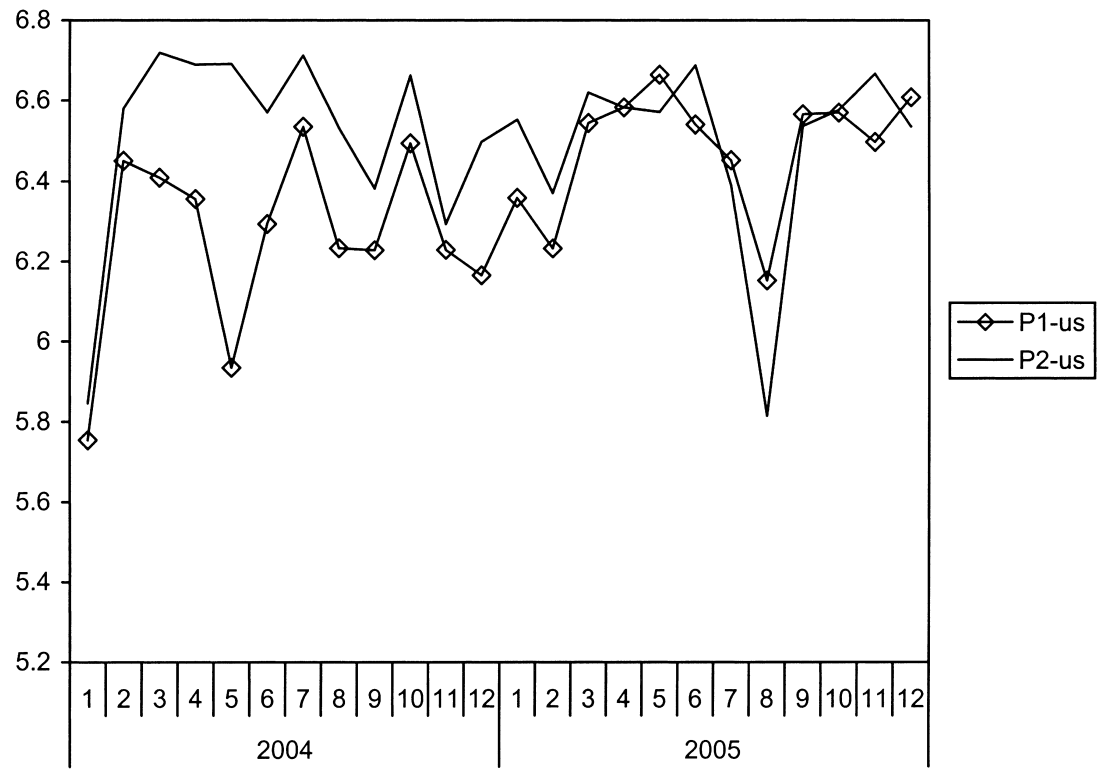

Fig. 6.3 Total monthly production at the U.S. plant, 2004-2005

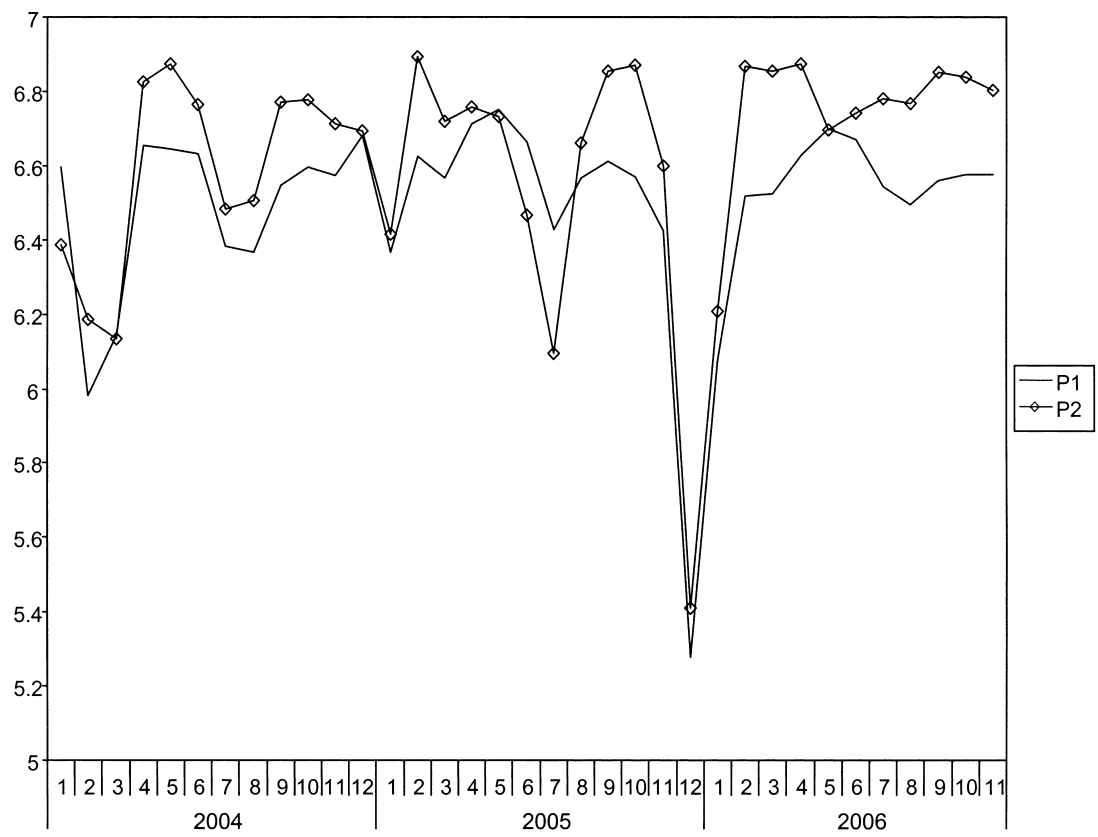

Fig. 6.4 Total monthly production at the Danish plant, 2004-2006 
OEE hours (total $2004=100$ )

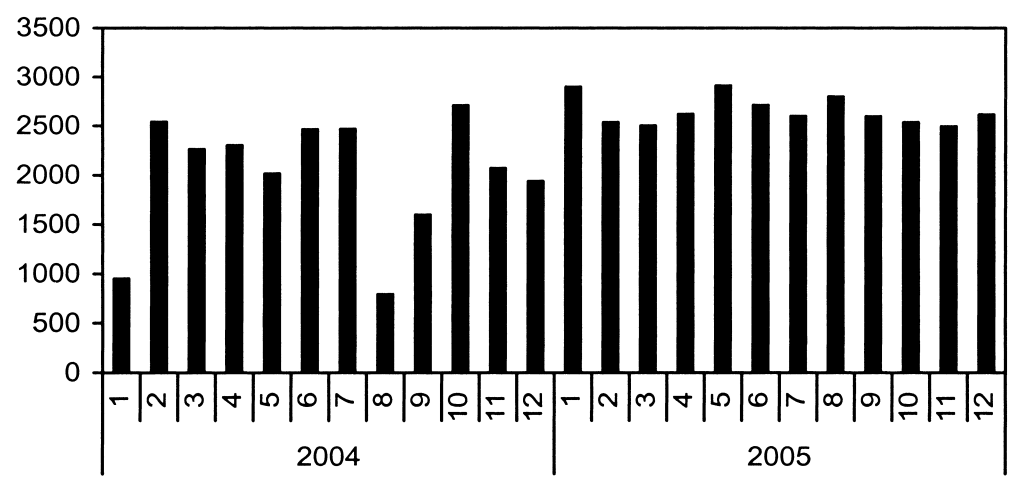

Fig. 6.5 Operating machine hours, U.S. plant, 2004 average $=100$

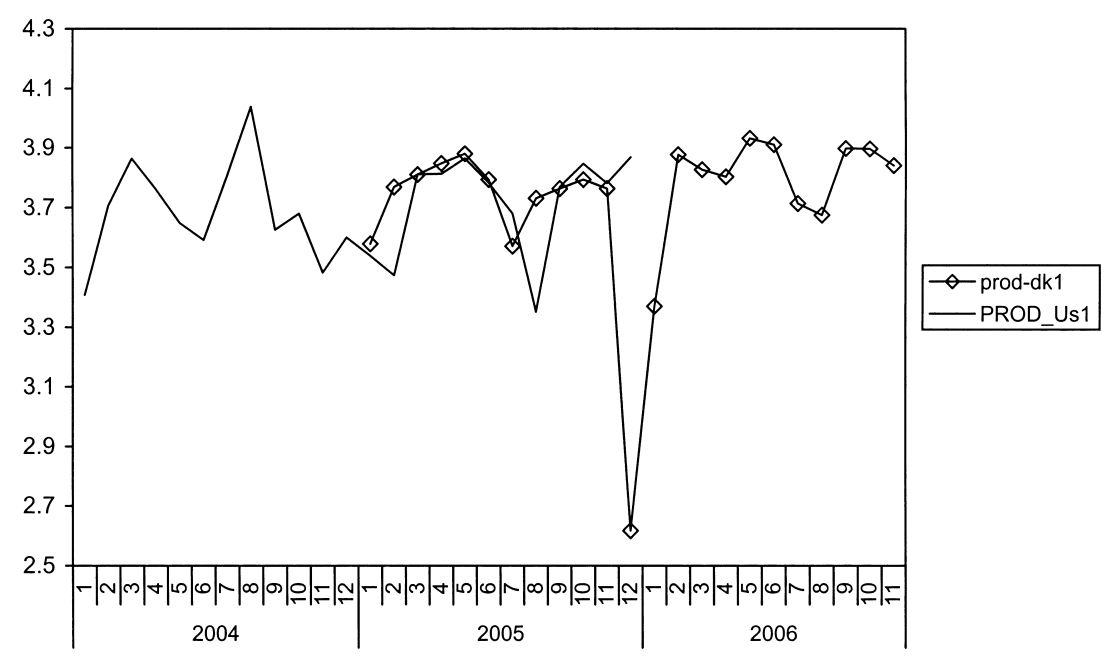

Fig. 6.6 Monthly productivity at the U.S. plant, 2004-2005

that the total number of operating hours of the machines has been increasing and has become much more stable over time.

Monthly data on labor productivity as measured by production per effective working hours are available for 2004 to 2005 (both products) for the U.S. plant and 2005 to 2006 (2004 to 2006) for production of P1 (P2) at the Danish plant. These data are displayed in figures 6.6 and 6.7, which show very similar levels of productivity. As for changes, labor productivity has been flat at the U.S. plant, whereas there is a weak positive growth at the Danish plant. Not too strong conclusions should be drawn from this as we do not have corresponding data from 2006 for the U.S. plant. With 


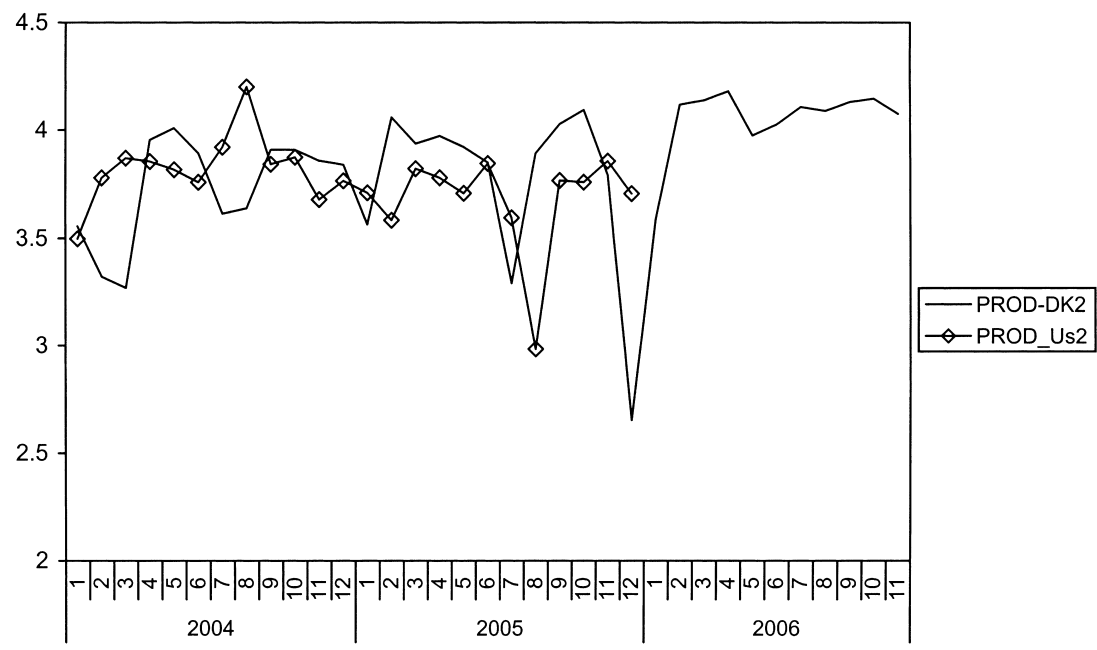

Fig. 6.7 Monthly productivity at the Danish plant, 2004-2006

Table 6.2 Reasons for downtime in the Danish and the U.S. plant in 2004 (in percent)

\begin{tabular}{lcc}
\hline Reason & U.S. plant & Danish plant \\
\hline Manning problems & 8.2 & 23.5 \\
Lack of supplies & 11.8 & 29.0 \\
Technical problems & 64.6 & 14.5 \\
Other reasons & 15.4 & 31.0 \\
Total & 100 & 100 \\
\hline
\end{tabular}

this caveat in mind, it seems that the major accomplishment of the U.S. plant's turnaround was an improvement in the maintenance and repair of the machinery (at least up to 2005). The group of new technicians employed and the reorganization of work have probably been key to the successful development at the U.S. plant.

Firm AB provided us with some scattered information on the handling and manning of the machines - the reasons for downtime at the U.S. and the Danish plant (see table 6.2). Unfortunately this is available for 2004 only and although we have tried our best to make the two statistics comparable, the comparison should be treated with due caution. The main reason for downtime at the Danish plant is technical problems followed by "other reasons." The HRM issues in the form of manning are considered to be substantially less important. Lack of manning is mainly due to sick absence and shortage of replacements. In the U.S. plant, "lack of supplies" is the most important cause of downtime and stops the production processes a number of times during the two month period covered by the statistics. Lack of personnel 
is another major factor at the U.S. plant, whereas technical problems are unimportant. This accords with our conclusions regarding the U.S. plant.

The improvements in performance of the U.S. plant in general have clearly influenced the decision of the board of the $\mathrm{AB}$ to expand production at the plant. Thus, during the first day of our visit at the plant our program had to be rescheduled due to the visit of the governor of the state, who made the announcement that there will be an expansion of the plant in the next few years, which will result in an increase of employment at the plant by a third by 2008 .

Attempts to increase productivity were also made at the Danish plant, and as we have seen from figures 6.3 and 6.5 , were met with some success. The goal here too was to increase actual production time (up-time) at each line from the previous 7.1 hours per day to 17.7 hours within a four-year time period. One central idea was to change the production into more shift work, similar to what had been done at the American plant. But it turned out to be much more difficult to get through with such dramatic changes in working hours. The management simply found itself faced with the well-paid workers regarding current working hour schedules as a right they were not going to give up willingly. As work peace was a key feature of this "model employer" firm, the strategy was to avoid conflicts as far as possible. The main thing that came out of these efforts was that workers at two filling lines are now working in a different way "as an experiment." In this experiment, new team leaders and new working schedules have been introduced.

The first change at the Danish plant was to give the team leaders more decision rights than before and conversely, to take some of the authority from the self-managed teams. ${ }^{7}$ New employees, all with a university degree, were hired into the positions as team leaders. One of the first changes was the introduction of a new time schedule for the teams manning the two "experimental" filling lines. Instead of the usual two eight-hour shifts with Saturday and Sundays free, a nine-hour working day with two fifteen-minute breaks and one thirty-five-minute break was adopted. Furthermore, unlike at the other lines, manning of the experimental lines is secured at all times. In many ways this means that the "right to manage" has been moved back to management. The authority of the teams is reduced considerably while the power of team leaders is strengthened. There are, however, also some costs associated with this transformation. Because the teams are not responsible anymore for the covering of sick-days for the team members, absence from work becomes visible again and has to be dealt with (by team leaders).

The transformation process has been difficult because workers did not

7. It should be noted that also the other plants in Denmark originally had production work organized in self-managed teams, but have abandoned the multitasking philosophy in recent years. For instance, this was the case in a relatively new plant that makes use of a new filling technology, which all the managers we talked with expected to be the next generation technology that will be adopted more widely in the industry. Self-managed teams have not been adopted in the firm's plants outside Denmark (except, as mentioned previously, at the U.S. plant where it was abandoned in 2003). 
want to abstain from what they considered to be well-deserved privileges. Thus, the local union representatives have not cooperated in the introduction of the new system, and occasionally actively resisted it. (Thus, there were even short strikes among production workers, which have not taken place in many years.) On the other hand, national level unions have provided some support in facilitating the changes. Help from lawyers specializing in labor relations has been instrumental in accomplishing even small changes. In addition to changes in time schedules and decision rights, another novelty is performance management meetings in order to focus on productivity improvements, development of standards for batch shifts, shortening of idle time, and increasing monitoring.

During our one-hour visit inside the plant, we observed a number of interruptions in filling, and it is obvious that the process of filling is critical for increasing up-time and improving productivity. On the technical front, a new filler line was introduced in June 2004. The filler line uses a superior technology and is twice as fast as the old ones. The new line can be considered as an implicit threat of job losses at other lines if their productivity is not improved. Still another threat facing the workers at the plant in Denmark is the company's plans to start up new production and expand current production sites abroad, including those in low-wage countries. Clearly, the likelihood of substitution of jobs from the Danish plant to other countries has created some additional pressure on the workers to accept management's plans for changes.

Next we briefly consider another Danish plant mentioned in the introduction to section 6.3. The main reason is that we were not, despite considerable efforts, able to obtain comparable data from our Danish main case plant, and therefore wanted to look at developments at this other plant as a kind of robustness check. Technologically the second Danish plant is identical to the U.S. plant; both produce products P1 and P2 and unlike the Danish main case plant, they do not do trial fillings (i.e., short batches). The monthto-month variations in production are also large at this Danish plant and production has increased in the period from 2004 to 2006.

It should be noted that some of the problems encountered in implementing the LEAN project at the main case plant were not present at this second plant. In particular, the resistance to the changes associated with the LEAN project was substantially weaker. Consequently, we would expect to observe a stronger improvement in productivity here. Unfortunately we do not have access to monthly series for the old product (P1) for 2004. But as can be seen from figure 6.8, the productivity development in 2005 and 2006 for this product shows no signs of improvement and does not lend support to our expectations of superior productivity performance here (compared to the other Danish plant). On the other hand, there is a strong increase in productivity for $\mathrm{P} 2$. However, this is most likely due to learning curve effects, as we are here observing production of a new product. Curiously enough, there were no signs of a similar learning effect at the U.S. plant. 


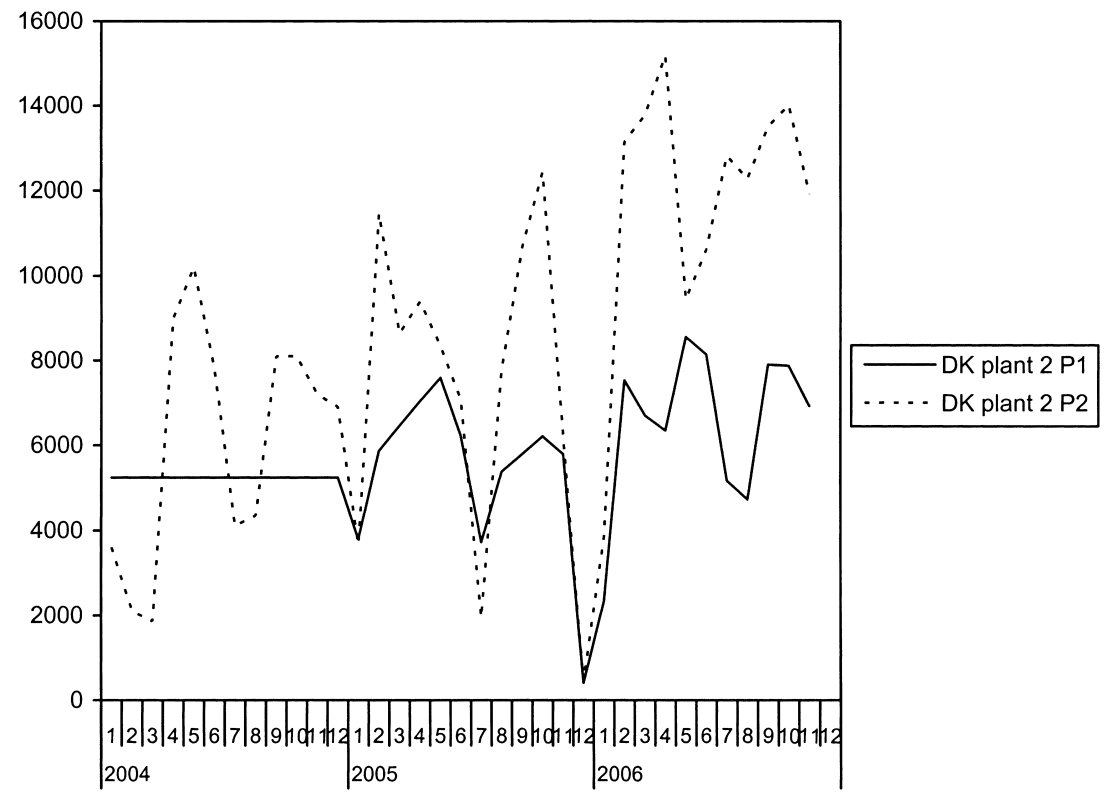

Fig. 6.8 Monthly labor productivity at the second Danish plant

\subsection{Summary and Conclusions}

The Danish and the American plants are more or less identical with respect to technology, product, IT, and also largely regarding overall management style. Firm $\mathrm{AB}$ has throughout the entire firm a labor-friendly approach to HRM with a strong emphasis on training, a relatively high level of nonwage benefits, and considerable promotion possibilities (especially for nonproduction workers) within the firm. It has strong values with respect to equal opportunities and so forth. However, there are also a number of differences between the two plants due to the different environments of operation. One difference is that workers at the Danish plant are paid higher than market wages, whereas at the American plant compensation is the competitive wage. The educational level of workers is another difference. This is considerably higher at the Danish plant. Management at the U.S. plant uses a lot of resources to keep trade unions out, while at the Danish plant resources have, at least until recently, been spent on cooperation and dealing with the local trade unions, which at times have acted quite militantly in resisting changes. The management structures are about the same down to the level of team leader. Both plants used to have self-managed teams, but these have been abandoned in the U.S. plant and in the Danish plant management is trying to disempower the teams. The main difference seems to be in how the change has been implemented at the two plants. 
The management at the U.S. plant was able to take back the right to manage quite swiftly, and was also able to introduce a new shift system and to hire and train completely new teams. The changes in work organizations and in job design were met with considerable resistance. Although the U.S. plant is a nonunion workplace, it had (according to its management) many features in common with unionized workplaces because it used to be organized as "silos;" that is, in departments with very little interaction. Therefore, absence of organized labor is not necessarily the sole explanation for why the transformation of the U.S. workplace was more successful than the Danish one. The recruitment was the major difficulty in this process because of the shortage of skilled workers.

At the Danish plant the major problem seems to be to get workers-and the local trade union in particular - to accept the proposed changes in the right to manage. As a result, changes have been introduced gradually and slowly and had to be implemented as an experiment. Why does it appear to be a greater challenge to change the organizational culture at the Danish plant? The presence of quite militant local union representatives is most certainly part of the story. Another factor that presumably has had some influence is that this is a much older plant with an organizational culture, the roots of which therefore go deeper. Originally the American plant had the same company policy as the mother company, but these policies stood out as quite different from the normal U.S. practices, while the differences in Denmark were smaller.

Still another contributing factor is how the change was designed; especially the absence of positive economic incentives that would make acceptance of the changes easier is a major difference as compared the U.S. plant. On the other hand, the Danish plant was already paying considerably higher wages than their local competitors, which clearly put some restrictions on this option. Hence, the incentives were more of the threat of job loss type. To which extent these implicit threats were conceived of as credible is hard to tell; one circumstance speaking in favor of that they were not, is the fact the plant is at the headquarters of the firm and that some of the operations in the firm are only carried out at the Danish plant and, therefore, are expected to remain there.

\section{References}

Acemoglu, D., P. Aghion, C. Lelarge, J. van Reenen, and F. Zilibotti. 2007. Technology, information and the decentralization of the firm. Quarterly Journal of Economics 122 (4): 1759-99.

Baker, G., R. Gibbons, and K. Murphy. 2002. Relational contracts and the theory of the firm. Quarterly Journal of Economics 117 (1): 39-83. 
Feldstein, M. 2003. Why is productivity growing faster? Journal of Policy Modeling 25 (5): 445-52.

Freeman, R., and M. Kleiner. 2005. The last American shoe manufacturers: Decreasing productivity and increasing profits in the shift from piece rates to continuous flow production. Industrial Relations 44 (2): 307-30.

Freeman, R., and E. Lazear. 1995. An economic analysis of works councils. In Works councils: Consultation, representation, and cooperation in industrial relations, ed. J. Rogers and W. Streeck, 27-51. Chicago: University of Chicago Press.

Hubbard, T. 2000. The demand for monitoring technologies: The case of trucking. Quarterly Journal of Economics 115 (2): 533-60.

Ichniowski, C., and K. Shaw. 2003. Beyond incentive pay: Insiders' estimates of the value of complementary human resource management practices. Journal of Economic Perspectives 17 (1): 155-80.

Lazear, E. 2000. Performance pay and productivity. American Economic Review 90 (5): 1346-61.

Smeets, V., and F. Warzynski. 2008. Wages, career dynamics and organizational differences between countries in a large multinational. Unpublished Manuscript.

van Ark, B., M. O’Mahoney, and M. Timmer. 2008. The productivity gap between Europe and the United States: Trends and causes. Journal of Economic Perspectives 22 (1): $25-44$. 